\title{
Advanced Hydraulic Hybrid Vehicle: "Taking a Sustainable Ride on the Green Vehicle Side"
}

\author{
Nirnimesh De, Tamojit Poddar \\ Department of Mechanical Engineering, Jadavpur University \\ India
}

\begin{abstract}
Today, with almost every major country joining the Global development race, the demand for fossil fuel is on the rise and there is a vehement need to look for alternative sources of fuel. One area of research taken up by Automobile companies has been the finding of practical and efficient solutions to procure fuel sources for vehicles. Apart from the use of Internal Combustion (IC) Engine, "Hydraulic Hybrid Vehicle" incorporates the use of another source of power to move the automobile. The most used source of power in present hybrids is electricity i.e. Electrical Motor or Generator. However, the electric hybrids did not reach its epitome neither did it become a properly optimized alternative. During this unstable condition, the novel Hydraulic Hybrid mechanism kissed the light of the innovative engineering world to replenish the dearth of fuel sources. In hydraulic hybrid, power comes from pressurized fluid in addition to the internal combustion engine propulsion that helps in better fuel economy than the conventional system. The hydraulic hybrids help in economizing fuel consumption by recovering and reusing the kinetic energy loss of the vehicle during braking and deceleration (i.e., Regenerative braking); and converting it into reusable potential energy gain inside the Hydro-Pneumatic Accumulator. When the vehicle accelerates again, the pressurized fluid provides the stored potential energy to the pump to deliver the power to move the vehicle. Thus, this innovative automobile stands tall and successful amongst the other contemporary vehicles due to it is more efficacious and well-organized nature.
\end{abstract}

Keywords: Fossil Fuel; Hydraulic Hybrid; Hydro-Pneumatic Accumulator; IC Engine; Regenerative Braking.

\section{Introduction}

An alternative to electric hybrid vehicles, hydraulic hybrids transfer kinetic energy generated during braking to an "accumulator" of pressurized fluid, which then provides with energy when the vehicle accelerates. This paper proposes a novel technology that used Hydraulic Hardware setup, resulting in the reduction of fuel consumption and therefore vehicle emissions - by recovering and then using the energy that's typically wasted. These hybrid setups recuperate energy more effectively than the contemporary electric hybrids and can improve fuel efficiency by about $20-25 \%$ for parallel systems and by over $45 \%$ for series combination. Figure-1 below clearly demonstrates the parallel, series and the combined structural setups. This novel approach is potent enough to extend brake life for the hybrid vehicles. With using CAES (Compressed Air Emission System) technology, we can count on volumetric compressor and expander as a solution for the plummet of recharging stations on power configuration of the system and storage of energy in the form of compressed air instead of the large batteries thus increasing space efficiency. This results in more braking which further paves the way for more energy capture. Thus, the above-mentioned Hydraulic Hybrid Automobile is an impactful and coherent solution to the scathing Energy crisis and Environmental Pollution.

\section{Materials and Methods}

\subsection{Hydraulic Hybrid Vehicle System (HHV System)}

The hydraulic hybrid system basically consists of a Fluid-Pump-Reservoir-Accumulator combination. In some advanced systems, hydraulic transformers are included in order to convert the output flow at any pressure manually. This process converts kinetic energy to potential energy that can be reused by the process called "Regenerative Braking". In the Figure 1 below, is the Hybridized powertrain schematic. The main essences of Hybridization of Powertrain are:

2.1.1. Recapture Kinetic energy during Breaking

2.1.2. Run Engine at Peak efficiency

2.1.3. Turn off Engine when vehicle stopped

2.1.4. High Peak Power 


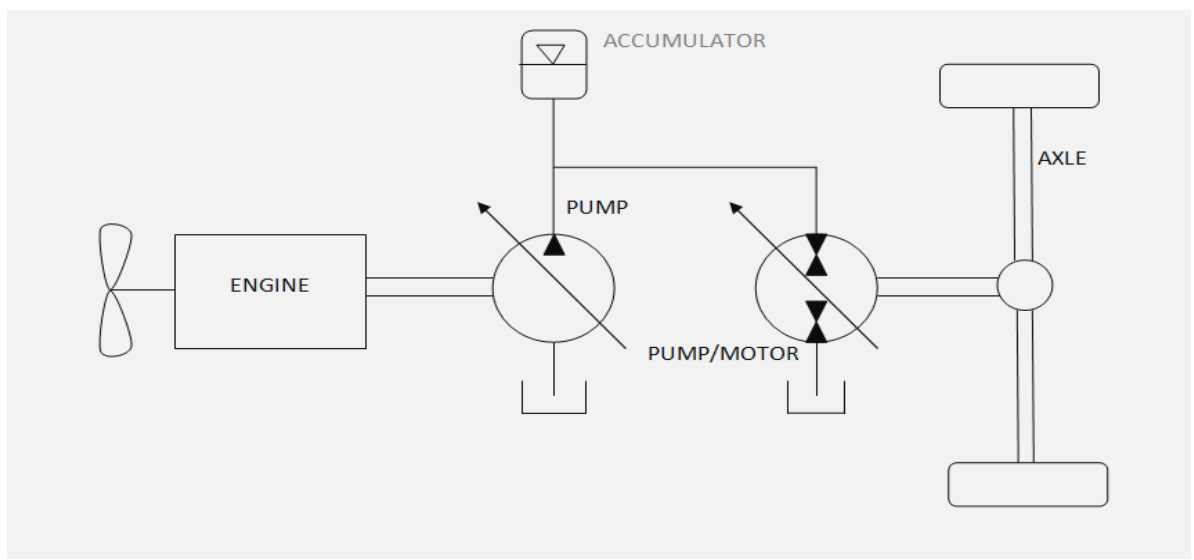

Figure 1. Hybridized Powertrain

\subsection{Types of HHVS}

Three types of hydraulic hybrids exist, depending on where the output from the pump goes to. In a parallel system, the pump provides the power to the engine during accelerating period. It has many engineering applications due to its advantages of easy refitting and high transmission efficiency. But however, an engine does not have full freedom to decouple with driving conditions compared with the series system. Therefore, the optimization is limited and the energy-saving efficiency is not as high. Also it does not possess the advantages of CVT (Continuously Variable Transmission). In a series system, the pump is directly connected to the wheel shaft. The series hybrid can decouple between engine and driving condition. The mechanical transmission parts of a traditional vehicle are annihilated. The Engine can work in best performance conditions, which can effectively improve fuel economy and reduce pollution emissions. It is easy to realize the continuously variable transmission (CVT) and drive/brake integrated control. We are mainly focusing on the "series-parallel hybrid system" that has the advantage of both series and parallel types. It can possess the best performance advantages of a hybrid powertrain under different driving situations. Therefore, fuel economy has the potential to be improved. However, its structure is complicated, and reliability of components is highly required. Its control system should ensure smooth switch during mode changes.

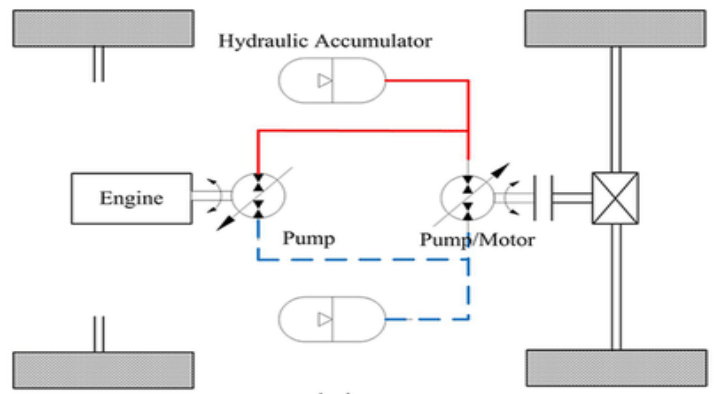

(a)

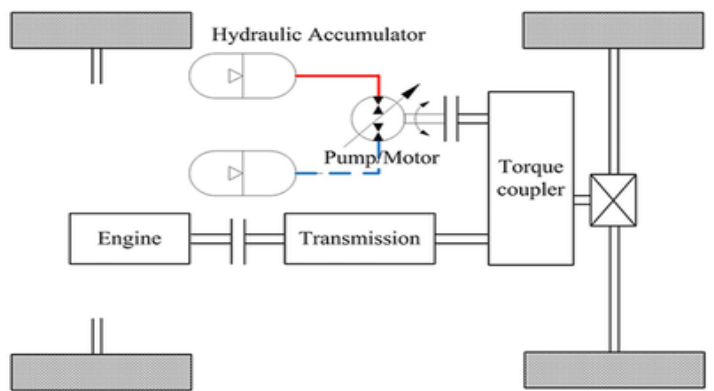

(b)

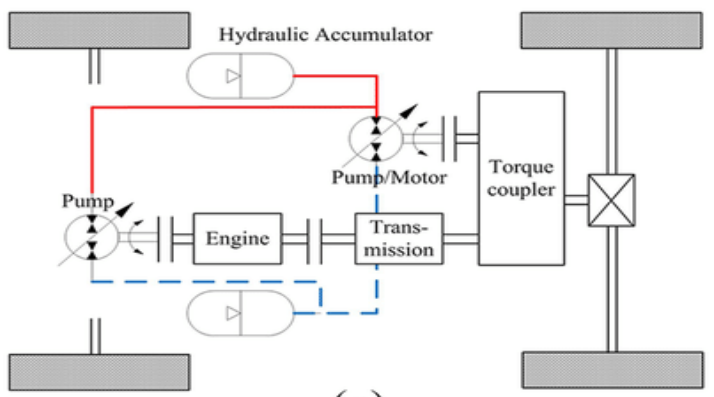

(c)

Figure 2. The Schematic of different types of hydraulic hybrid vehicles: (a) Series System, (b) Parallel System \& (c) Series-Parallel Combined System 
The above Figure 2 shows the schematic of 3 different types of Hydraulic Hybrid Vehicle systems. Hydraulic transmission system provides the variable speed ratios between engine and wheels which remove the sudden changes during the gear-shifting. Continuously variable transmissions (CVTs) are also unaffected by gearshift discontinuities during the shifting process, thus providing passengers with a comfortable and uninterrupted ride. The advantage of the CVT is that by minimizing the power loss of an engine, engines can operate at peak efficiency or at constant engine speeds. Moreover, CVTs are structurally simple and easily maintained. However, CVTs cannot bear with the frictional forces generated due to the torsional moments of engines because of its values exceeding the limit of the belt or chain strengths. The overall difference drawn from the above are summarized in the Table 1 shown below.

Table 1. Comparison between the Series and Parallel Hydraulic Hybrid Vehicle System

\begin{tabular}{|l|l|l|}
\hline Properties & $\begin{array}{l}\text { Series } \\
\text { HHVS }\end{array}$ & $\begin{array}{l}\text { Parallel } \\
\text { HHVS }\end{array}$ \\
\hline Efficiency & Higher & Lower \\
\hline Fuel Consumption & Lower & Higher \\
\hline Emission & Less & High \\
\hline Engine on-time & Lower & Higher \\
\hline Cost Effective & More & Less \\
\hline Break Wear & Lower & Higher \\
\hline
\end{tabular}

\subsection{Merits/ Advantages of Hydraulic Transmission Systems over CVTs}

2.3.1. Steady Transmission: Hydraulic transmission devices operate by using hydraulic oil, which is nearly incompressible at ordinary pressures and using continuously flowing hydraulic oil to make gearshifts. Because hydraulic oil has shock absorbing capacities, hydraulic buffer devices can be installed in the oil lines to provide steadily operating transmissions.

2.3.2. Light weight and compact size: In contrast to mechanical and electrical transmissions, hydraulic transmissions are substantially lighter and smaller under identical output power conditions. Thus, hydraulic transmissions have low inertia and are highly responsive.

2.3.3. High Capacity: Hydraulic transmissions can readily receive large forces and torsional moments.

2.3.4. Readily obtainable infinitely variable speeds: In hydraulic transmissions, infinitely variable speeds can be obtained by regulating fluid flow rates. The adjustment ratio can vary widely from 1:1 to 2000:1. Extremely low speeds are easily achieved.

\section{Procedure}

For the vehicle transmission systems, hydraulic transmission systems can achieve similar continuously variable speed functions. In principle, hydraulic pumps convert mechanical energy provided by engines into fluid hydraulic energy. Finally, hydraulic motors convert high pressure hydraulic energy into mechanical energy to drive the vehicles. To obtain continuously variable speed functions, only the hydraulic motor or hydraulic pump valve opening must be adjusted. The propel circuit is adapted to exchange hydraulic fluid power with the pump/motor. The pump is adapted to transfer power from a prime mover of the mobile work vehicle to the propel circuit. The hydraulic accumulator is adapted to exchange hydraulic fluid power via an accumulator isolation valve with the propel circuit when the hydraulic system is configured in the hybrid mode. The accessory circuit is adapted to receive hydraulic fluid power from the hydraulic accumulator, at least when the hydraulic system is configured in the hydrostatic mode and the accumulator isolation valve is closed. Various embodiments will have described in detail with reference to the drawings, wherein like reference numerals represent like parts and assemblies throughout the several views. The present disclosure relates generally to hydraulic circuit architectures for use in work vehicles. A hydraulic circuit architecture, in accordance with the principles of the present disclosure, can include a propel circuit and a work circuit. In certain embodiments, the propel circuit and the work circuit can be powered by a same hydraulic pump structure (e.g., a hydraulic pump or a hydraulic pump/motor). In certain embodiments, the hydraulic pump structure includes a single drive pump (e.g., only one pump, only one pumping rotating group, only one pump/motor, etc.). In certain embodiments, the propel circuit can include a hydraulic accumulator and a hydraulic propulsion pump/motor for powering propulsion elements (e.g., wheels, tracks, etc.) of the work vehicle through a drive train. The work circuit can include various actuators for powering work components such as lifts, clamps, buckets, blades, and other structures. In a preferred embodiment, the hydraulic architecture is used on a forklift $\mathbf{5 0}$ where the propulsion circuit powers a drive train 114 coupled to drive wheels $\mathbf{5 4}$ of the forklift $\mathbf{5 0}$, and the work circuit includes valving and actuators (e.g., hydraulic cylinders) for raising and lowering a fork $\mathbf{5 2}$ of the forklift $\mathbf{5 0}$, for front-to back tilting of the fork 52, and for left and right shifting of the fork $\mathbf{5 2}$. 


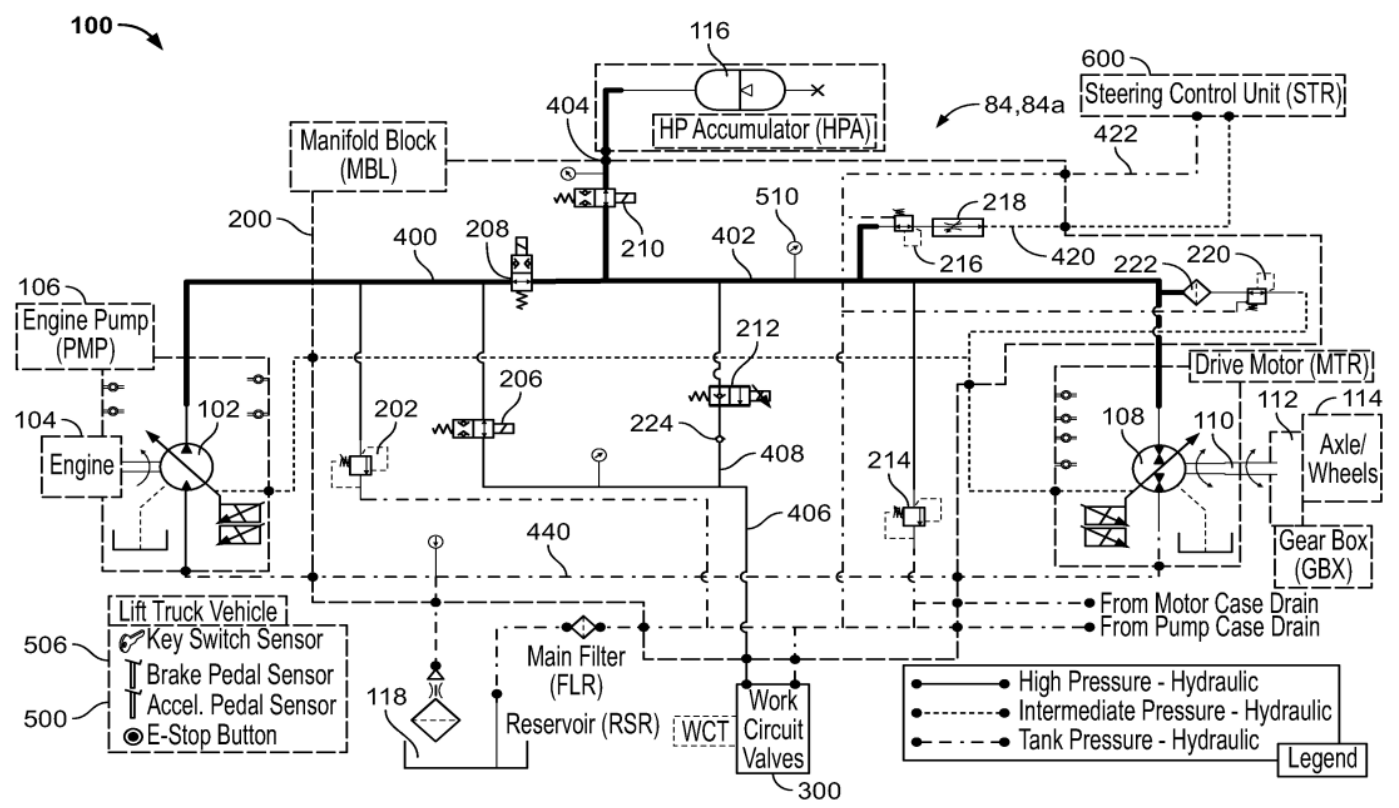

Figure 3. Schematic diagram of the proposed Hydraulic system having the advance features

In certain embodiments, the hydraulic accumulator of the propulsion circuit can be used to provide numerous functions and benefits. For example, the provision of the hydraulic accumulator allows the hydraulic pump/motor and prime mover powering the propulsion circuit to be consistently operated at peak efficiency or near peak efficiency. Moreover, accumulated energy in the hydraulic accumulator can be used to provide power for starting a power source (e.g., a prime mover, a diesel engine, or other engine) used to drive the hydraulic pump/motor. Additionally, the hydraulic accumulator can be used to provide propulsion functionality even when the power source coupled to the hydraulic pump/motor is not operating. Similarly, the hydraulic accumulator can be used to provide work circuit functionality even when the power source coupled to the hydraulic pump/motor is not operating. Furthermore, by operating the propulsion hydraulic pump/motor as a motor during braking/deceleration events, energy corresponding to the deceleration of the work vehicle can be back-fed and stored by the hydraulic accumulator for later re-use to enhance overall efficiency of the work vehicle.

In certain embodiments, one (i.e., a single) hydraulic pump/motor (e.g., a hydraulic pump/motor 102, shown at FIG. 2) is used to power both the propulsion circuit and the working circuit. In such an embodiment, a circuit selector (i.e., a mode selector) can be provided for selectively placing a high-pressure side of the hydraulic pump/motor in fluid communication with either the propulsion circuit or the working circuit. The circuit selector can include one or more valves.
Furthermore, a cross-over valve can be provided for selectively providing fluid communication between the propulsion circuit and the work circuit. By opening the cross-over valve, power from the hydraulic accumulator can be used to drive one or more actuators of the work circuit thereby allowing for actuation of the actuators of the work circuit, even when the power source is turned off. When the circuit selector has placed the pump/motor in fluid communication with the propulsion circuit for propelling the work vehicle, the various components of the work circuit can be actuated by opening the cross-over valve. Additionally, when the circuit selector has placed the pump/motor in fluid communication with the work circuit, the hydraulic accumulator can be used to provide for propulsion and steering of the work vehicle. It will be appreciated that a steering component is preferably incorporated into the hydraulic propulsion circuit. When the power source is turned off, the hydraulic accumulator can be used to power the steering component, power the propulsion elements, and/or power the various components of the work circuit. It will be appreciated that such activities can be conducted individually or simultaneously. The crossover valve can provide a variable size orifice.

In certain embodiments, the hydraulic pump/motor coupled to the power source is an open circuit pump/motor having a rotating group and a swash plate that is adjustable to control an amount of hydraulic fluid displaced by the pump/motor per rotation of a pump/motor shaft by the power source. In certain embodiments, the swash plate has an overcenter configuration. When the pump/motor is 
operating as a pump, the swash plate is on a first side of center and the power source rotates the pump/motor shaft in a first direction such that hydraulic fluid is pumped through the pump/motor from a low-pressure side in fluid communication with a reservoir/tank to a high-pressure side in fluid communication with the circuit selector. When the hydraulic pump/motor is operated as a motor, the swash plate may be moved to a second side of center and hydraulic fluid from the hydraulic accumulator is directed through the pump/motor from the highpressure side to the low-pressure side thereby causing the pump/motor shaft to rotate in the same rotational direction that the pump/motor shaft rotates when driven by the power source. In this way, hydraulic energy from the hydraulic accumulator can be used to start modes including use of the power source. The propulsion pump/motor can also be an open circuit pump/motor having a low-pressure side connected to the reservoir/tank and a high-pressure side that connects to the hydraulic pump/motor coupled to the power source through the circuit selector. The propulsion pump/motor can include a rotating group and a swash plate that can be adjusted to control displacement of the propulsion pump/motor for each revolution of a shaft of the propulsion pump/motor. The swash plate can be an over-center swash plate that allows for bi-directional rotation of the shaft of the propulsion pump/motor. For example, when the swash plate is on a first side of center, hydraulic fluid flow through the pump/motor from the high-pressure side to the lowpressure side can drive the shaft in a clockwise direction. In contrast, when the swash plate is on a second side of center, hydraulic fluid flow through the propulsion pump/motor in a direction from the high-pressure side to the low-pressure side causes rotation of the shaft in a counterclockwise direction.
In this way, the propulsion pump/motor can be used to drive the work vehicle in both forward and rearward directions. Moreover, during a braking event, the propulsion pump/motor can function as a pump and can direct hydraulic fluid from the reservoir to the hydraulic accumulator to charge the hydraulic accumulator thereby capturing energy associated with the deceleration. Thus, the propulsion pump/motor and the hydraulic accumulator provide a braking/deceleration and energy storage function. It will be appreciated that in other embodiments, valving can be used in combination with non-over-center pump/motors to provide the same or similar functionality as the overcenter pump/motors described above. The non-overcenter pump/motors and the valving can be used as the hydraulic pump/motor coupled to the power source and/or can be used as the propulsion hydraulic pump/motor that is coupled to the drivetrain. According to the principles of the present disclosure, methods of operating the hydraulic circuit architecture provide smooth and beneficial use of the work machine 50. Hydraulic hybrid vehicles typically operate at pressures below a maximum system operating pressure to allow for energy storage capacity in an accumulator and to increase operating displacement of a pump and motor to increase pump and motor efficiency. However, this typically limits the torque that can be delivered quickly to a drivetrain when climbing a hill, accelerating hard, or any other time that high torque is desired. This lack of instantaneous torque can be eliminated by isolating the high-pressure accumulator from the system and operating the vehicle in a typical hydrostatic mode where pressure (and thereby torque) can be raised very quickly and to pressure levels that may exceed an operating pressure of the high-pressure accumulator.

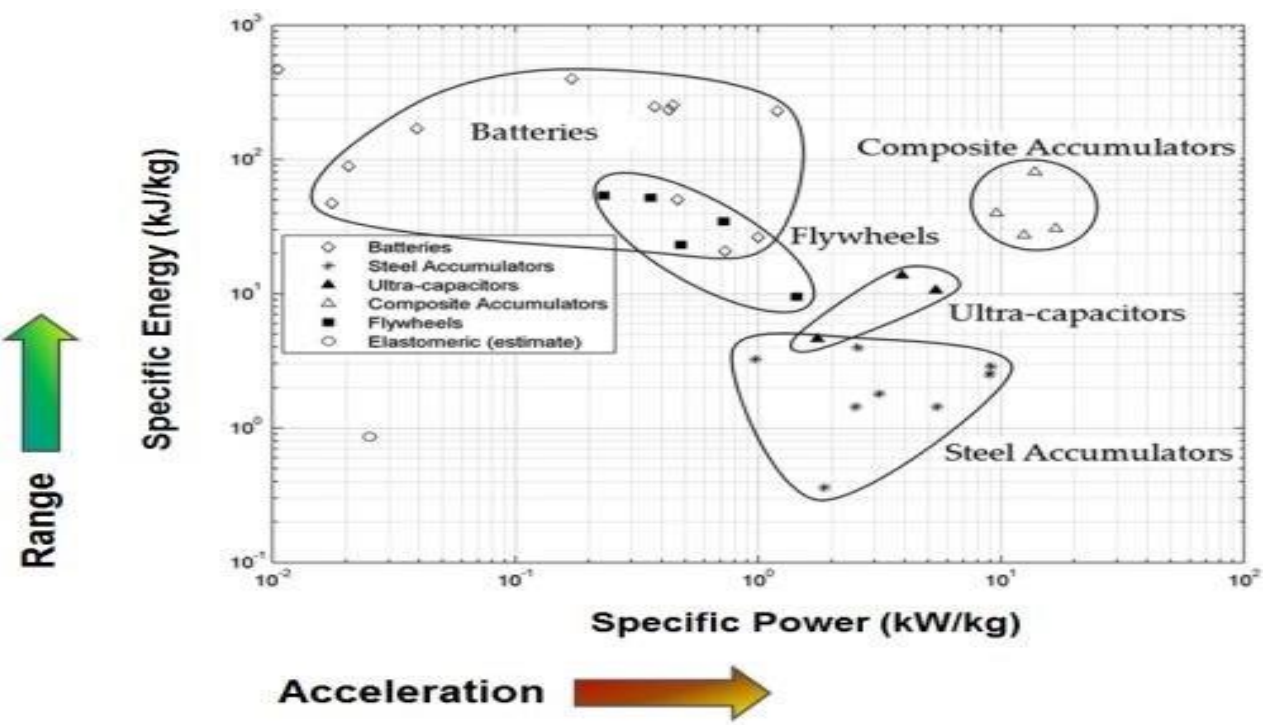

Figure 4. Graph showing Energy Storage density V/s Regenerative Braking Energy 
The process is very simple and efficient. According to a Sep 2016 article by Lightning Hybrids CEO Tim Reeser, customers running hydraulic hybrid vehicles report a significant reduction in fuel usage and $\mathrm{CO} 2$ emissions. $\mathrm{NO}_{\mathrm{X}}$ emissions are also reportedly cut by $50 \%$. Other benefits of hydraulic hybrid technology include:

- Does not require as much space or payload sacrifice as battery hybrids;

- Much less expensive than electric hybrid drivetrains;

- Reduces engine exhaust during acceleration;

- Adds power/torque allowing for engine downsizing (typically 600-800 lb-ft for UPS van);

- $\quad>100 \%$ improvement in brake component life.

Conventional batteries (and even flywheels) lack the high specific power density of lightweight composite accumulators that enables efficient storage and reuse of regenerative braking energy in heavy vehicles.

Wheel motors are important parts in a hydraulic hybrid vehicle with wheel motors. When driven by in-wheel motors, part of the transmission mechanism is eliminated. The structure of the vehicle is simple and the transmission efficiency is high, which is beneficial to the space layout of the whole vehicle \& the traction force and climbing capacity of the vehicle can be improved by working with in-wheel motor.

\section{Discussions}

\subsection{Proposed HHV System Design}

An ideal hydraulic hybrid vehicle with wheel motors is shown below to improve vehicle power performance and fuel economy. This designed vehicle can work in drive and brake mode, and its operating principles are designed. The details of design are described from review and comparison of [5].

\subsection{System Configuration}

The model eliminates the mechanical transmission parts of a traditional vehicle, and hydraulic power system is applied. Four wheels are directly rotated by four variable displacement wheel motors. This vehicle can decouple between engine and driving condition. Engine can be downsized due to the auxiliary drive of high-pressure accumulator. Vehicle fuel economy can be improved significantly by recovering the braking energy. Also, vehicle dynamics, minimum ground clearance and off-road performance can be improved due to four variable displacement wheel motors which are shown in the simplified Figure 5.

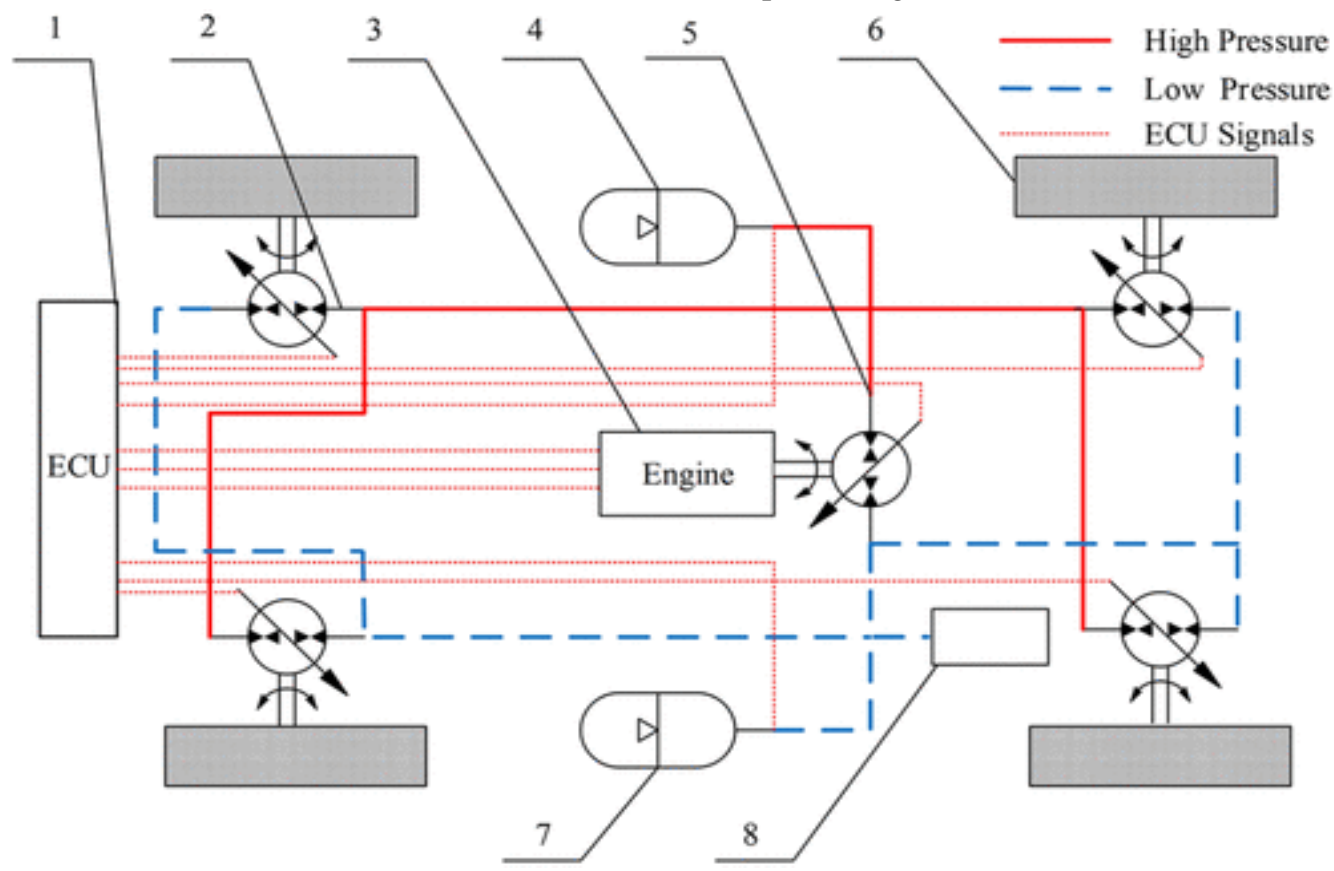

Figure 5. Schematic of an Ideal Hydraulic Hybrid Vehicle with wheel motors

INDEX: 1: ECU; 2: Variable Displacement Wheel Motor; 3: Engine; 4: High-Pressure Accumulator; 5: Variable Displacement Pump; 6: Wheel; 7: Low-Pressure Reservoir; 8: Recharging Oil Device. 


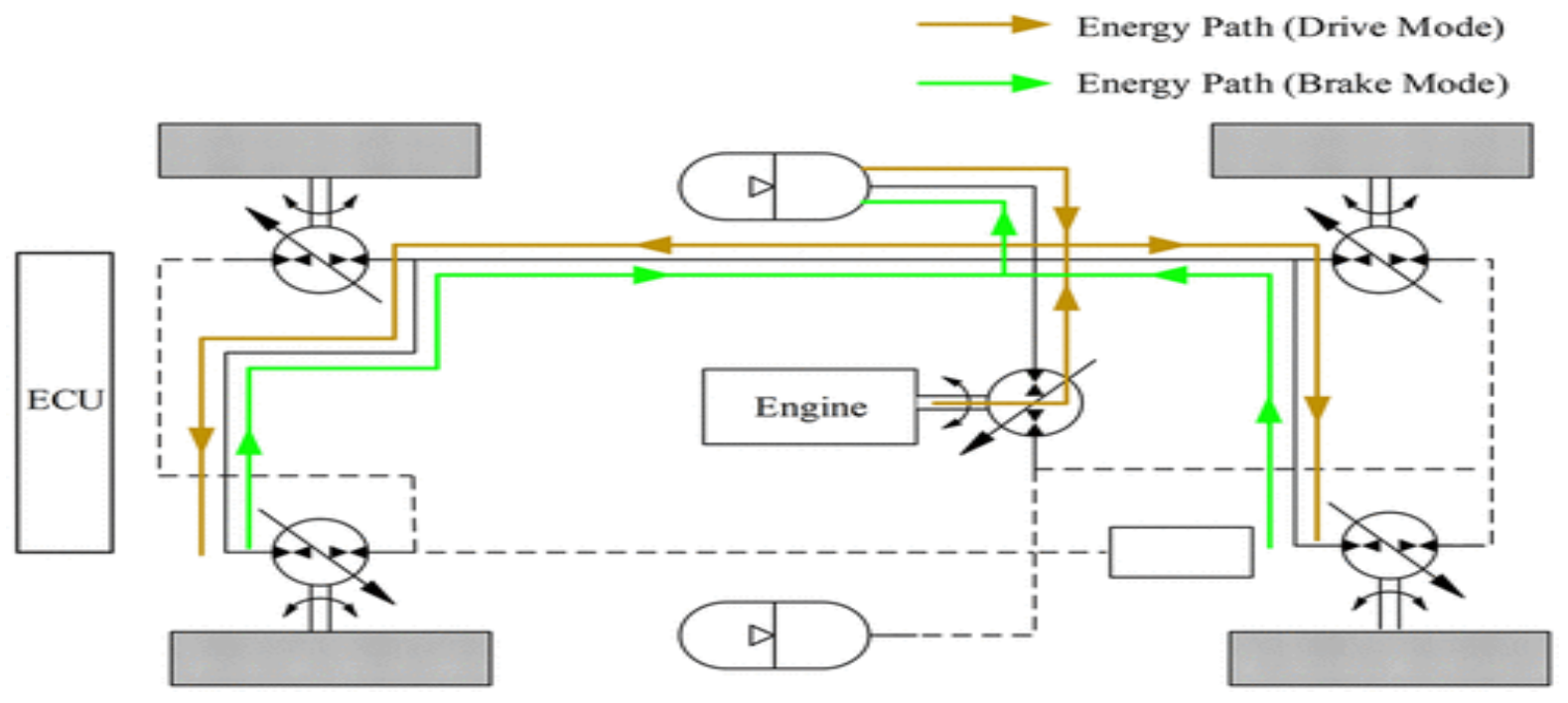

Figure 6. Energy Transfer path in both Drive and Brake Mode

\subsection{Operating Principles}

The proposed model vehicle can be used in drive and brake mode, and its energy transfer path is shown in Figure 6 above.

\subsection{Drive Mode Energy Transfer}

4.4.1. The electronic control unit (ECU) detects the pressure of the accumulator when starting or accelerating. If the pressure is lower than a certain lower limit, the engine works and drives the variable displacement pump to supply high-pressure oil to the hydraulic system. If the pressure is higher than the upper limit, the accumulator independently supplies high-pressure oil to drive variable displacement wheel motors; meanwhile, the engine idles or shuts down. The engine and the high-pressure accumulator can work together to offer output power when rapid acceleration occurs. Therefore, engine peak power can be decreased. This proposal can overcome the shortcomings of low efficiency and large pollution emissions of engine during starting and accelerating.

4.4.2. When driving at a constant speed, there are two conditions according to the pressure of accumulator. If the pressure is lower than a lower limit, the engine works in best fuel economy area. Excess high-pressure oil is stored in the accumulator. Otherwise, the accumulator releases energy and the engine idles or shuts down. Therefore, the engine works in best performance area intermittently.

4.4.3. During reverse driving, the ECU detects reverse gear signal, and then the rotational direction of variable displacement wheel motors is changed.
Its energy transfer path is the same as forward driving.

\subsection{Brake Mode Energy Transfer}

The ECU detects brake pedal signal, and then the engine idles or shuts down immediately. The variable displacement pump no longer provides the hydraulic system with high-pressure oil. The ECU adjusts the displacement of the wheel motor to negative value. The variable displacement wheel motor works as a pump driven by the inertia of vehicle. Therefore, the kinetic energy is converted into hydraulic energy and stored in the high-pressure accumulator. When the high-pressure accumulator is full, excess high-pressure oil will flow back to lowpressure reservoir through relief valve. It causes oil temperature to rise rapidly. At this point, traditional brake system should work immediately.

\subsection{Power Source System of the proposed HHV}

The power source system mainly consists of an engine, a variable displacement pump and a highpressure accumulator. A simulation block diagram of power source system is shown in Figure 7. The engine speed controller uses a PID controller. The control process is summarized as follows:

4.6.1. The first controller is called upper controller, and it calculates the required power of the variable displacement wheel motor based on signals from oil pressure and flow sensors.

4.6.2. The working status and desired power of engine are determined according to the driver's gear 
selection and power management strategy which is decided by the upper controller.

4.6.3. The engine operating mode (economy or power) is decided by the driver's mode selection. Then, the desired operating point of the engine is determined from look-up tables.

4.6.4. Throttle opening is adjusted by the electronic throttle model. Then, the torque is applied to variable displacement pump. Engine actual operating point is determined by actual throttle opening and actual engine speed.

4.6.5. The variable displacement pump model calculates actual pump speed that is the actual engine speed.

4.6.6. The engine speed controller makes the engine track aim at engine speed by changing the displacement of variable displacement pump according to engine speed error.

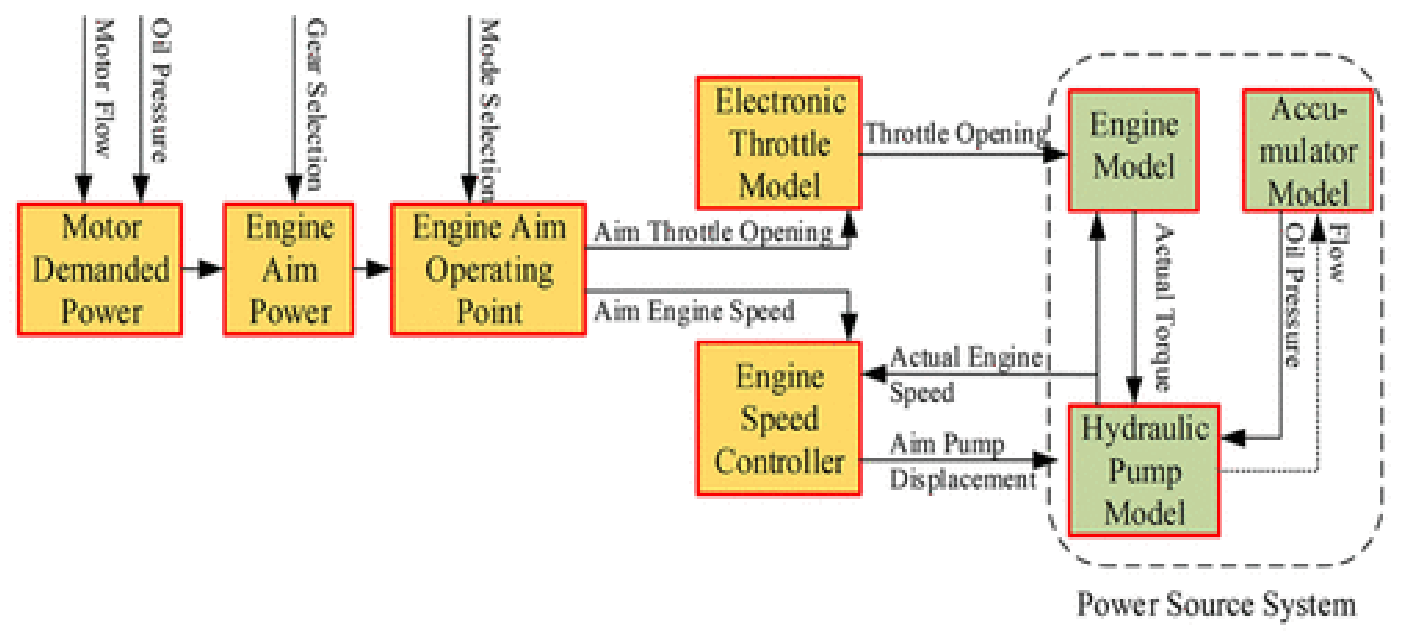

Figure 7. Block Diagram of the proposed HHV Power Source System

\subsection{Improvement Targets}

Areas where the additional improvements are needed to reduce costs and weights and improve system performance include: drive unit optimization, hydraulic energy storage system optimization, hydraulic controls and hydraulic energy transfer fluids. The below Table 2 provides a summary of these improvement potential areas for heavy-duty HHVs (Hydraulic Hybrid vehicles).

Table 2. Heavy-Duty Hydraulic Hybrid Vehicle Technological Improvement Potential

\begin{tabular}{|c|c|}
\hline Technology/Issue & $\begin{array}{c}\text { Improvement/Optimization } \\
\text { Potential }\end{array}$ \\
\hline $\begin{array}{c}\text { Hydraulic pumps } \\
\text { and motors }\end{array}$ & $\begin{array}{c}\text { Engine downsizing, internal } \\
\text { combustion engine and } \\
\text { hydraulic pump/motor, engine } \\
\text { and hydraulic controls }\end{array}$ \\
\hline $\begin{array}{c}\text { Hydraulic controls } \\
\text { and energy transfer } \\
\text { fluids }\end{array}$ & Reliability, cost \\
\hline $\begin{array}{c}\text { Hydraulic energy } \\
\text { storage system }\end{array}$ & Efficiency, life, cost \\
\hline $\begin{array}{c}\text { System integration } \\
\text { Engine and transmission, } \\
\text { OBD, hydraulic drive and } \\
\text { engine, SCR dosing }\end{array}$ \\
\hline
\end{tabular}

\subsection{Performance Goals}

The 21st Century Truck Partnership has also identified performance goals for heavy-duty HHVs in a February 2013, report, Roadmap and Technical White Papers. A summary of these goals is shown in Table 3.

Table 3. Technology Goals for Heavy-Duty Hydraulic Hybrid Vehicles

\begin{tabular}{|c|l|}
\hline Technology & \multicolumn{1}{c|}{ Goals } \\
\hline & $\bullet$ Hydraulic pumps/motors: \\
Hydraulic & higher pressure limits $(7,000-$ \\
Energy & 10,000 psi, currently 5,000 psi) \\
Conversion & $\bullet$ Optimize: efficiency, weight \\
Devices & and noise reduction \\
& $\bullet$ Efficiency: 96-97 percent \\
& (currently 94 percent) \\
& $\bullet$ Develop non-permanent \\
& magnet motor technology \\
& $\bullet$ Optimize hydraulic circuit \\
& design \\
Hydraulic & $\bullet$ Higher operating pressure \\
Controls & valves \\
& $\bullet$ Reduce cost, improve \\
& efficiency and reliability
\end{tabular}




\begin{tabular}{|c|l|}
\hline $\begin{array}{c}\text { Hydraulic } \\
\text { Energy Storage }\end{array}$ & $\begin{array}{l}\bullet \text { Improve system life to meet life } \\
\text { targets of vehicle } \\
\bullet \text { Increase specific energy and } \\
\text { energy densities (higher } \\
\text { maximum pressure, lower } \\
\text { weight) } \\
\bullet \text { Optimize manufacturing } \\
\text { process for high volume } \\
\text { production }\end{array}$ \\
\hline Hydraulic & $\begin{array}{l}\bullet \text { Develop cost-effective fluids, } \\
\text { wider operating temperature } \\
\text { range } \\
\bullet \text { Complies with biodegradability } \\
\text { and fire resistance requirements } \\
\text { Fluids }\end{array}$ \\
& Engine operation
\end{tabular}

\section{Recommendations}

The Future prospect of this work lies in the implementation of CAES (Compressed Air Engine Storage) Technology so as to convert compressed air into electrical engine with mobile turbine generator and by reversing it the compressed air can be reused as a substitution of battery. Further scope of work lies in the utilization of WPT (Wireless Power Transmission) that possess the potential to procure Electric energy from Renewable Sustainable Energy Sources (i.e., Solar and Wind majorly) with no emission or fossil fuel combustion being involved. It might be possible to attain a prospective future by the incorporation of the Hybrid of 3 above mentioned technologies into green vehicle.

\section{Conclusion}

The proposed Hydraulic Hybrid Vehicle (HHV) thus connects all the dots required to suffice the necessities of a more fuel efficient and effective automobile. The usage of the technology of compressed air storage and later its utilization for power generation reduces the consumption of conventional sources of fuel. This promotes Environmental benefit as well as it assures costefficiency. Vehicles tapping the potential of batteries have failed to gain a prime success owing to their higher prices and more space requirements. Hence if considered and taken into serious consideration, the proposed novel HHV is the future of the Modern Advanced Hybrid Vehicle system and the solution of red altering critical crisis like Environment pollution, Energy crisis, Degradation of Natural Fuel (Fossil Fuel) etc. It also possesses the potential to outperform the contemporary fossil fuel and batterybased vehicles.

\section{Reference}

[1] Reprinted with permission from Frontiers of Engineering, Reports on Leading-Edge Engineering: Wireless Charging of Electric Vehicles, 2017 by the National Academy of Sciences, Courtesy of the National Academies Press, Washington, D.C.https://www.powerelectronics.com/markets/auto motive/article/21864097/wireless-charging-of-electri c-vehicles.

[2] Tao, L., Jincheng, Z., Shuwen, W., Fangde, Gu. (2013). Logic threshold-based energy control strategy for parallel hydraulic hybrid vehicles. Research Journal of Applied Sciences, Engineering and Technology, 6, 2339-2344.

[3] Sakota, Z., Jovanovic, Z., Diligenski, Dj., Zivanovic, Z., Nikolic, D. (2013) Improving the fuel economy by using hydraulic hybrid powertrain in passenger cars Machines, technologies, materials. ISSN 1313-0226 ISSUE 4/2013.

[4]Steelhead Composites, plot courtesy of W. J. B. Midgley and D. Cebon, "Comparison of Regenerative Braking Technologies for Heavy Goods Vehicles in Urban Environments," Proceedings of the Institution of Mechanical Engineers, Part D: Journal of Automobile Engineering, vol. 226, pp. 957-970.

[5] Fronczak, F. J., and Beachley, N. H. "An Integrated Hydraulic Drive Train System for Automobiles," Fluid Power, R. Heron, ed., Elsevier Applied Science,London, 1988, pp. 199-215.

[6]Kress, J. H., "Hydrostatic Power-Splitting Transmissions For Wheeled Vehicles Classification and Theory of Operation," Society of Automotive Engineers, No. 680549, 1968.

[7] Wu, B., Lin, C., Filipi, Z., Peng, H., Assanis, D. (2002).Optimization of Power Management Strategies for a Hydraulic Hybrid Medium Truck Proceedings of the 2002 Advanced Vehicle Control Conference. Hiroshima Japan

[8] Bowns, D. E., Vaughan, N. D., and Dorey, R. E., "Design Study of a Regenerative Hydrostatic Split Power Transmission for a City Bus," I Mech E Hydrostatic Transmissions for Vehicle Application, Coventry, Engl, 1981, pp 29-38.

\section{Acknowledgement}

First and foremost, thanks to God, the Almighty, for his showers of blessings throughout our research work to complete it successfully. There is no such 
International Journal of Sustainable Energy Development (IJSED), Volume 8, Issue 1, 2020

acknowledgement in specific because no financial assistance or academic guidance was sought for this research work. We (both the authors of this paper) solely acknowledge each other for the extreme support and sheer hard work of both the individuals for the completion of this research work successfully. 